OPEN ACCESS

Edited by:

Andreas Reif,

University Hospital Frankfurt, Germany

Reviewed by:

Martin Schäfer,

Kliniken Essen-Mitte, Germany Harald Scherk,

Vitos Klinikum Riedstadt, Germany

*Correspondence:

Gabriele Sachs

gabriele.sachs@meduniwien.ac.at

Specialty section:

This article was submitted to Mood and Anxiety Disorders,

a section of the journal

Frontiers in Psychiatry

Received: 27 January 2020 Accepted: 29 October 2020 Published: 23 November 2020

Citation:

Sachs G, Berg A, Jagsch R, Lenz G and Erfurth $A$ (2020) Predictors of Functional Outcome in Patients With Bipolar Disorder: Effects of Cognitive Psychoeducational Group Therapy After 12 Months.

Front. Psychiatry 11:530026 doi: 10.3389/fpsyt.2020.530026

\section{Predictors of Functional Outcome in Patients With Bipolar Disorder: Effects of Cognitive Psychoeducational Group Therapy After 12 Months}

\author{
Gabriele Sachs ${ }^{* *}$, Andrea Berg ${ }^{1}$, Reinhold Jagsch ${ }^{2}$, Gerhard Lenz ${ }^{1}$ and Andreas Erfurth ${ }^{1,3}$ \\ ${ }^{1}$ Department of Psychiatry and Psychotherapy, Medical University of Vienna, Vienna, Austria, ${ }^{2}$ Department for Clinical and \\ Health Psychology, University of Vienna, Vienna, Austria, ${ }^{3}$ First Department of Psychiatry and Psychotherapeutic Medicine, \\ Klinik Hietzing, Vienna, Austria
}

Background: Cognitive deficits are known as a core feature in bipolar disorder. Persisting neurocognitive impairment is associated with low psychosocial functioning. The aim of this study was to identify potential cognitive, clinical and treatment-dependent predictors for functional impairment, symptom severity and early recurrence in bipolar patients, as well as to analyze neurocognitive performance compared to healthy controls.

Methods: Forty three remitted bipolar patients and 40 healthy controls were assessed with a neurocognitive battery testing specifically attention, memory, verbal fluency and executive functions. In a randomized controlled trial, remitted patients were assigned to two treatment conditions as add-on to state-of-the-art pharmacotherapy: cognitive psychoeducational group therapy over 14 weeks or treatment-as-usual. At 12 months after therapy, functional impairment and severity of symptoms were assessed.

Results: Compared to healthy controls, bipolar patients showed lower performance in executive function (perseverative errors $p<0.01$, categories correct $p<0.001$ ), sustained attention (total hits $p<0.001$ ), verbal learning (delayed recall $p<0.001$ ) and verbal fluency ( $p$-words $p<0.002$ ). Cognitive psychoeducational group therapy and attention predicted occupational functioning with a hit ratio of $87.5 \%$. Verbal memory recall was found to be a predictor for symptom severity (hit ratio $86.8 \%$ ). Recurrence in the follow-up period was predicted by premorbid IQ and by years of education (hit ratio $77.8 \%)$.

Limitations: Limitations of the present study result mainly from a small sample size. The extent of cognitive impairment appears to impact occupational disability, clinical outcome as well as recurrence rate. This result must be interpreted with caution because statistical analysis failed to show higher significance.

Conclusions: Bipolar patients benefit from cognitive psychoeducational group therapy in the domain of occupational life. Deficits in sustained attention have an impact on occupational impairment. Implications for treatment strategies are discussed. Further evaluation in larger studies is needed.

Keywords: bipolar disorder, cognitive function, psychosocial functioning, occupational impairment, symptom severity, recurrence, cognitive psychoeducational group therapy 


\section{INTRODUCTION}

Growing evidence suggests a considerable gap between syndromal and functional recovery among bipolar patients (1). Bipolar disorder (BD) is a severe mental illness; the course of the disease and the clinical outcome can be quite diverse. Treatment of $\mathrm{BD}$ often requires long-term medication and subsequently treatment adherence. There is a close relationship between treatment adherence and neurocognitive impairment (2). Neurocognitive deficits are known as a core feature in $\mathrm{BD}$ (3), including euthymic BD (4-6), subgroups (7) and are present during all stages (8) with a heterogeneous profile (4). Bipolar patients show poor performance in most cognitive domains, in processing speed, attention, verbal memory and executive functioning; in particular, context processing performance and associative learning are impaired $(9,10)$. Cognitive deficits are similar in bipolar I and bipolar II patients (11). Bipolar patients with psychosis exhibited more poorly on memory and executive function and had lower psychosocial functioning predicting limited recovery (12). There is not enough evidence so far for cognitive deficits being progressive in $\mathrm{BD}$. A meta-analytic study did not support the hypothesis of a progressive decline of cognitive deficits (13). Cognitive dysfunction seems to be stable over time, only dysfunction in verbal recall was found to show a progressive course in a 5-year follow-up study (14). Medial temporal dysfunction (15) and reduced white matter integrity (16) have been suggested to be involved with verbal memory impairment early in the course of bipolar I disorder.

Psychosocial dysfunction may differ when patients with firstand multiple-episode BD are compared. Repeated episodes may contribute to higher impairment in multiple areas of psychosocial functioning. Clinical factors such as depressive symptoms seem to have a negative impact on functioning (17). Persisting neurocognitive impairments are also found to be associated with low psychosocial functioning (18-20), specifically with significant impairment in work, family and social life, beyond the acute phases of the illness and depending on the patient's own evaluations of their subjective functioning (21).

There is a need for further knowledge regarding predictors of the course of the disorder. Previous number of mixed episodes, subdepressive symptomatology, number of hospitalizations and older age were found to predict functional outcome. Bonnín et al. (22) demonstrated that subdepressive symptomatology together with neurocognitive impairments related to verbal memory and executive functions are predictor variables of long-term functional outcome in BD. The number of hospitalizations for depressive episodes and illness duration were associated with a reduction in occupational functioning in patients suffering from BD (23). Ryan et al. (24) examined impact of cognition on work status and underemployment in euthymic BD patients. Patients with $\mathrm{BD}$ who have better cognitive functioning are more likely to be employed. After accounting for number of mood episodes patients with $\mathrm{BD}$ who are unemployed/unable to work have greater difficulties processing emotional information and on executive tasks comprising a shifting or interference resolution component compared to $\mathrm{BD}$ patients who are employed. Bonnín et al. (25) examined predictors of functional outcome after a manic episode and showed that number of past depressive episodes, psychotic symptoms at index episode, and Body Mass Index (BMI) predict worse outcome after 6 months follow-up.

There is evidence that maintenance pharmacotherapy in conjunction with psychological interventions can improve the outcome (26). Adjunctive psychosocial interventions (27-36), including web-based and mobile approaches have been suggested to enhance symptomatic and functional outcome $(37-43)$ in patients with BD -comprising adolescents (44)-, as well as in patients with subthreshold manifestations such as cyclothymic disorder (45). Presence of mixed episodes, full medication adherence and therapeutic blood levels of mood stabilizers were found predictive to attend a psychoeducation program (46). In a study with 55 patients with BD I and II in remission, 16-session psychoeducation seemed to be ineffective to prevent mood episodes or improve functioning (47). Functional remediation, a novel group intervention, showed efficacy in improving the functional outcome of a sample of euthymic bipolar patients as compared with treatment as usual $(48,49)$. Improvement in psychosocial functioning after functional remediation has been shown to be maintained after 1-year follow-up (50).

Clinical features and cognition related to functional outcome may have important effects on the overall therapeutic outcome. There is little evidence which clinical and neurocognitive variables would best predict the functional outcome in BD patients.

Aim of the present study was to identify potential cognitive, clinical and treatment-dependent predictors on functional impairment, symptom severity and early recurrence in patients with $\mathrm{BD}$. As an additional predictor, the impact of cognitive psychoeducational group therapy [CPEGT, (51)] on psychosocial function was explored. Furthermore, it was assessed whether bipolar patients and healthy controls differ regarding neurocognitive performance in executive functions and sustained attention.

\section{METHODS}

\section{Participants}

Remitted bipolar patients were recruited consecutively from psychiatric outpatient and inpatient units at the Department of Psychiatry and Psychotherapy, Medical University of Vienna, Austria $(N=43)$ with the following inclusion criteria: age between 18 and 65 years, diagnosis of bipolar I or II disorder according to DSM-IV TR criteria using the Structured Clinical Interview for DSM-IV (SCID) (52) and the MINI [Neuropsychiatric Interview, (53)], at least two episodes in the last 3 years or three episodes in the last 5 years, ongoing medication with mood stabilizers and remission. Remission was defined by the following scores: Beck Depression Rating Scale $<18$ [BDI, (54)], Manie-Selbstbeurteilungsskala $<14$ [MSS: German version of the Self-Report Manic Inventory, SRMI, (55)], Bech Rafaelsen Mania Scale <9, [BRMAS, (56)], Bech Rafaelsen Melancholia Scale $<26$ [BRMES, (57)].

Exclusion criteria were intellectual disability, history of substance abuse, neurological disease, as well as any medical condition that could affect neuropsychological performance. 
Patients were also excluded if they had participated in any structured psychological intervention, such as psychoeducation or cognitive remediation, within the past 2 years.

To assess neurocognitive performance in bipolar patients in comparison to healthy volunteers, 40 controls matched by age, gender and years of education were included into the study. Using the MINI it was ensured that the controls had no antecedent of neurological disease, no current diagnosis or history of psychiatric illness, current or previous alcohol/substance dependence or abuse, and that they were not taking psychotropic medication.

All participants, patients and controls, were fluent in German. The study was conducted in accordance with the ethical principles of the Declaration of Helsinki and Good Clinical Practice. The study protocol was approved by the Vienna University Hospital Ethics Committee. All subjects received extensive information about the study and gave written informed consent for their participation before they were enrolled in the study.

\section{Assessments}

Demographical and clinical assessment: In addition to the SCID and MINI, all patients were evaluated with BDI, MSS, BRMES, and BRMAS.

Demographical and clinical information were obtained from clinical charts and patient interviews (age, gender, years of education, duration of illness, bipolar subtype, number of manic, hypomanic and depressive episodes, history of psychosis, current medication). The severity of symptoms was assessed using the Clinical Global Impression scale [CGI, (58)].

Functional impairment in areas of vocational, social and family was rated applying the Sheehan Disability Scale [SDS, (59)].

Neuropsychological assessment: At baseline bipolar patients completed a neurocognitive test battery including different tasks divided into cognitive domains: estimated premorbid IQ, using a German multiple choice vocabulary test, the MehrfachwahlWortschatz-Test [MWT, (60)]; attention/vigilance, which was evaluated by the Continuous Performance Test, Identical Pairs [CPT-IP, (61)]; executive function (set shifting, planning and response inhibition) using the Computerized Wisconsin Card Sorting Test [WCST, (62)]; verbal learning and memory which were assessed by the Verbal Learning and Memory Test [VLMT, (63)] and verbal fluency using the Regensburger Word Fluency Test [RWT, (64)].

Reassessment: Patients underwent clinical and functional reassessment after completion of the intervention (14 weeks after baseline evaluation). Furthermore, a follow-up assessment was performed after 12 months.

At 12 months functional impairment in areas of vocational, social and family life was assessed applying the SDS, severity of symptoms was rated using the CGI. The recurrence rate was established. Recurrence was diagnosed when full DSM-IV TR criteria for a new affective episode were met; adherence toward psychopharmacology was measured using the Medication Compliance Questionnaire [MCQ, (65)].

\section{Interventions}

Of the 43 bipolar patients, 19 ( 12 female) were randomly assigned to the intervention group and 24 to the treatment as usual (14 female). There were no significant differences between the groups with regard to age, gender, BD I/BD II, rapid cycling, duration of illness, number of episodes, education, being in a job or current medication (choice of mood stabilizer, taking an antipsychotic). All 43 patients received state-of-the-art pharmacotherapy and completed the study.

Patients were randomized to either cognitive psychoeducational group therapy (CPEGT) (51, 66) over 14 weeks or to treatment as usual (TAU information group).

CPEGT consisted of 14 sessions; the duration of each session was $90 \mathrm{~min}$. The contents of CPEGT were distributed in the following way: session 1-introduction and overview, session 2-explanatory models of bipolar disorders, session 3-pharmacotherapy, session 4-side effects of medications, session 5-depression I-symptoms and coping strategies, session 6-depression II-increase of pleasant activities, session 7depression III-modification of depressive cognitive patterns, session 8-depression IV-relapse prevention, session 9-mania Isymptoms and coping strategies, session 10-mania II-relapse prevention, session 11-healthy lifestyle I-regular rhythm of life without alcohol and drugs, session 12-healthy lifestyle IIthe "Life Chart Method," session 13-healthy lifestyle III-goal attainment and communication strategies, session 14-review.

Additionally, between two and four sessions were performed with relatives.

Patients in the control group also had regular group sessions. The thematic focus was on reading a book about BD ["Sturzfliegen" by Vasak and Katschnig, (67)]. In addition, three questions and answers sessions were provided. Booster sessions were offered after 6 and 9 months for both treatment and control group.

\section{Statistical Analysis}

Data were analyzed using the Statistical Package of Social Sciences (SPSS Inc. 19 ${ }^{\text {th }}$ Version, Chicago, IL, USA). Differences in demographic characteristics and neurocognitive measures between patients with bipolar disorder and controls were studied using independent $t$-test for continuous variables. Chi-square was used to examine categorial data. Pearson correlations were calculated to identify which demographic, clinical and neurocognitive variables were linked to functional impairment (three domains assessed by the SDS), symptom severity (CGI) and recurrence rate (number of episodes in the follow-up period of 12 months). The demographic variables were age, gender, years of education. The clinical variables were CPEGT, duration of illness, BDI, MSS, number of affective episodes in the 12 months prior to the start of the study, history of psychosis, current medication. The neuropsychological variables were premorbid IQ (MWT), attention/vigilance (CPT-IP, CPT -IP total hits, total false), WCST categories (categories correct, perseverative errors, verbal learning and memory (VLMT, immediate recall, delayed recall) and verbal fluency (RWT, $p$-words, $s$-words).

All significant variables (demographic, clinical and neurocognitive) that were found to correlate with functioning, 
CGI and recurrence rate were introduced in a five backwards stepwise logistic regression analyses. Additional variables from the literature, including correlations between clinical, neurocognitive measures and functional outcome, were considered (23). Backward (Wald) logistic regressions were used to predict functioning, CGI and recurrence rate and estimate percentage variance accounted for by variables of interest.

Level of significance was set at $\leq 0.05$.

\section{RESULTS}

\section{Demographic and Clinical Characteristics}

Thirty three patients with bipolar I disorder and 10 patients with bipolar II disorder were included; of the 43 bipolar patients seven were rapid cyclers. The age (mean $\pm \mathrm{SD}$ ) was $42.2 \pm 10.9$ years, the years of education $16.0 \pm 4.0$. The average duration of illness was $15.3 \pm 10.3$ years; the number of affective episodes in the 12 months prior to the start of the study was $3.4 \pm 2.4$ [0-8]. Fifteen patients (34.9\%) had a history of psychotic symptoms, $26(60.5 \%)$ were female. All 43 patients received at least one mood stabilizer (lamotrigine 17, sodium valproate/valproic acid 16, lithium carbonate 11, carbamazepine 3); additional medications were atypical antipsychotics (22 patients), antidepressants (10) and hypnotic drugs (benzodiazepines/zolpidem: 5). For an overview of all demographic, clinical and neurocognitive characteristics see Table 1.

\section{Neurocognitive Performance in Bipolar Patients Comparison With Healthy Controls}

Neurocognitive performance was compared to 40 healthy controls matched by age, sex and years of education. Compared to healthy controls, patients with BD showed lower performance in executive functions as measured by the WCST (perseverative errors $p \leq 0.01$, categories correct $p \leq 0.001$ ), in sustained attention (CPT-IP total hits $p \leq 0.001$ ), in verbal learning (VLMT delayed recall $p \leq 0.001$ ) and verbal fluency (RWT $p$-words $p$ $\leq 0.002$ ).

\section{Pearson Correlations of Demographic, Clinical, and Neurocognitive Characteristics of Patients With BD (Table 2)}

CPT-IP false hits $(r=0.36, p=0.023)$ and WCST total correct $(r$ $=0.41 ; p=0.009$ ) correlated with number of affective episodes in the 12 months prior to the start of the study.

\section{Effects of Therapy}

\section{Effects of Therapy on Number of Episodes}

As previously communicated $(68,69)$, after 14 weeks of therapy an improvement in illness concepts and adherence was observed in both the CPEGT group and the TAU group; after further 12 months the number of manic episodes was significantly decreased in both groups as compared to the 12 months before the intervention. A significant reduction of the number of depressive episodes was observed after CPEGT; after TAU the number of depressive episodes remained unchanged.
TABLE 1 | Demographic, clinical and neurocognitive characteristics of patients with BD at baseline $(n=43)$

\begin{tabular}{|c|c|c|}
\hline Variables & Mean & SD \\
\hline Age, years & 42.2 & 10.9 \\
\hline Education, years & 16.0 & 4.0 \\
\hline Duration of illness, years & 15.3 & 10.3 \\
\hline \multirow{2}{*}{$\begin{array}{l}\text { Number of affective episodes in the } 12 \text { months } \\
\text { prior to the start of the study }\end{array}$} & 3.4 & 2.4 \\
\hline & $N$ & $\%$ \\
\hline Female & 26 & 60.5 \\
\hline Male & 17 & 39.5 \\
\hline History of psychotic symptoms & 15 & 34.9 \\
\hline \multicolumn{3}{|l|}{ Medication } \\
\hline Lithium carbonate & 11 & 25.6 \\
\hline Sodium valproate/valproic acid & 16 & 37.2 \\
\hline Lamotrigine & 17 & 39.5 \\
\hline Carbamazepine & 3 & 7.0 \\
\hline Atypical antipsychotics & 22 & 51.1 \\
\hline Antidepressants (SSRI) & 10 & 23.3 \\
\hline Hypnotic drugs (benzodiazepines/zolpidem) & 5 & 11.6 \\
\hline Neurocognition & Mean & SD \\
\hline MWT & 30.5 & 4.2 \\
\hline WCST total correct & 68.3 & 13.9 \\
\hline WCST perseverative errors & 19.2 & 18.7 \\
\hline CPT-IP Total hits & 0.47 & 0.2 \\
\hline CPT-IP Total false & 0.16 & 0.1 \\
\hline VMLT immediate recall & 9.95 & 2.8 \\
\hline VMLT delayed recall & 7.04 & 2.0 \\
\hline RWT $p$-words & 12.60 & 4.8 \\
\hline RWT s-words & 21.11 & 3.8 \\
\hline
\end{tabular}

MWT, Mehrfach-Wortschatz-Test: assessment of premorbid intelligence; WCST, Wisconsin Card sorting test; CPT-IP, Continuous Performance Test, identical pairs; VMLT, Verbal Learning and Memory Test; RWT, Regensburger Word Fluency Test.

\section{Functional Impairment, Severity of Symptoms, and Early Recurrence: Pearson Correlations}

SDS score impairment in areas of vocational functioning correlated with CPEGT ( $r=0.381 ; p=012$ ) and CPT-IP (false $r=-0.411 ; p=0.006)$. Scores in CGI correlated with verbal learning immediate recall $(r=0.338, p=0.038)$ and verbal learning delayed recall $(r=0.336, p=0.039)$. Finally, recurrence was found to correlate with verbal learning immediate recall $(r=$ $0.381, p=0.018)$ and verbal learning delayed recall $(r=0.397, p$ $=0.014)$.

\section{Regression Analyses}

As shown in Table 3, CPEGT and CPT-IP (total false) predicted the amount of occupational impairment (hit ratio of $87.5 \%$ ). VLMT delayed recall was found to be a predictor for symptom severity as measured by CGI (hit ratio $86.8 \%$ ). Recurrence in the follow-up period of 12 months was predicted by MWT and years of education (hit ratio $77.8 \%$ ).

Of these predictors reaching the previously defined significance level of $p \leq 0.05$, CPEGT (with regard to 
TABLE 2 | Pearson correlations of demographic, clinical and neurocognitive characteristics of patients with BD at baseline $(n=43)$.

\begin{tabular}{|c|c|c|c|c|c|c|c|c|c|}
\hline & MWT & $\begin{array}{l}\text { CPT-IP } \\
\text { hits }\end{array}$ & $\begin{array}{l}\text { CPT-IP } \\
\text { false }\end{array}$ & $\begin{array}{c}\text { WCST } \\
\text { total }\end{array}$ & $\begin{array}{l}\text { WCST } \\
\text { persev. }\end{array}$ & $\begin{array}{c}\text { VMLT } \\
\text { immediate }\end{array}$ & $\begin{array}{l}\text { VMLT } \\
\text { delay }\end{array}$ & $\begin{array}{c}\text { RWT } \\
p \text {-words }\end{array}$ & $\begin{array}{c}\text { RWT } \\
\text { s-words }\end{array}$ \\
\hline Gender & -0.12 & -0.01 & 0.06 & 0.08 & 0.15 & 0.22 & 0.11 & 0.22 & -0.10 \\
\hline Age & $0.30^{*}$ & $-0.17^{\star}$ & -0.07 & -0.00 & $0.20^{\star}$ & -0.23 & $-0.33^{*}$ & 0.18 & 0.10 \\
\hline Years of education & $0.24^{*}$ & -0.01 & -0.14 & 0.01 & -0.13 & 0.01 & -0.18 & 0.16 & 0.22 \\
\hline Illness duration & 0.25 & -0.12 & 0.09 & 0.10 & 0.12 & -0.13 & -0.04 & 0.26 & -0.10 \\
\hline Number of episodes & 0.00 & 0.14 & $0.36^{\star}$ & $0.41^{\star \star}$ & -0.17 & -0.11 & -0.04 & 0.01 & -0.21 \\
\hline Psychosis & $-0.34^{\star}$ & 0.15 & -0.10 & 0.15 & -0.11 & -0.02 & 0.11 & -0.01 & 0.09 \\
\hline Atypical antipsychotics & -0.26 & -0.17 & -0.08 & 0.01 & -0.04 & -0.01 & 0.14 & -0.05 & 0.03 \\
\hline
\end{tabular}

${ }^{*} p \leq 0.05,{ }^{* *} p \leq 0.01$

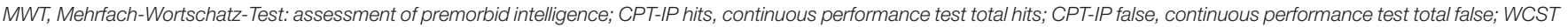

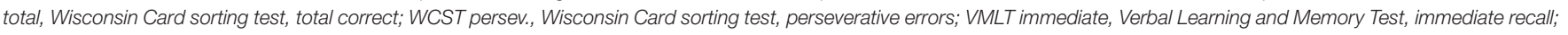

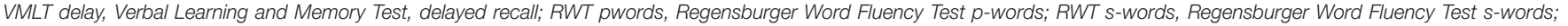
Number of episodes, number of affective episodes in the 12 months prior to the start of the study.

TABLE 3 | Functional impairment, severity of symptoms and early recurrence: results of regression analyses.

\section{Regression Wald $\operatorname{Exp}(B) p$ \\ coefficient B}

\begin{tabular}{|c|c|c|c|c|}
\hline \multicolumn{5}{|l|}{ Occupational impairment (SDS) } \\
\hline $\begin{array}{l}\text { Cognitive psychoeducational group } \\
\text { therapy (CPEGT) }\end{array}$ & -2.30 & 6.68 & 0.10 & $0.010^{\star \star}$ \\
\hline CPT-IP total false & -11.73 & 5.45 & 0.00 & $0.020^{*}$ \\
\hline \multicolumn{5}{|l|}{ CGI } \\
\hline Atypical antipsychotics & -1.82 & 3.03 & 0.16 & 0.082 \\
\hline VLMT delayed recall & 0.48 & 4.24 & 1.62 & $0.039^{*}$ \\
\hline \multicolumn{5}{|l|}{ Early recurrence } \\
\hline VLMT delayed recall & 0.34 & 3.64 & 1.41 & 0.056 \\
\hline MWT & 0.36 & 4.93 & 1.43 & $0.026^{\star}$ \\
\hline Years of education & -0.38 & 5.68 & 0.69 & $0.017^{\star}$ \\
\hline
\end{tabular}

${ }^{*}$ Significance level was set at ${ }^{*} p \leq 0.05,{ }^{* *} p \leq 0.01$.

SDS, Sheehan Disability Scale at 12-month follow-up; CPT-IP total false, Continuous Performance Test total false at baseline; CGI, Clinical Global Impression scale at 12month follow-up; early recurrence, occurrence of an affective episode within the 12month followup period; VLMT delayed recall, Verbal Learning and Memory Test, delayed recall at baseline; MWT, Mehrfach-Wortschatz-Test: assessment of premorbid intelligence at baseline.

occupational impairment) was the only predictor reaching a significance level of $p \leq 0.01$.

No significant predictors were found for social disability and family-life impairment.

\section{DISCUSSION}

Patients with $\mathrm{BD}$ are impaired in the domains of attention, verbal memory and executive functions (4). The results of our study confirm these findings showing specific deficits in sustained attention, executive function, verbal memory and also in verbal fluency. Remitted bipolar patients had clinically significant cognitive deficits compared to healthy controls. The patients in this study were characterized by a particularly long duration of illness (average of 15.3 years). Looking at the association between number of affective episodes in the 12 months prior to the start of the study and cognitive function a significant correlation was found between number of affective episodes and impairment in the domain of sustained attention (continuous performance test: total false). Unfortunately, due to the small sample size $(N=43)$, it was not possible to assess which type of past episodes (depressive, manic or mixed) led to the reduction of sustained attention in these remitted patients. Clearly, further research on neurocognitive dysfunction in rapid cycling bipolar disorder (70) is suggested by our finding. Data on cognitive impairment in bipolar patients might have important clinical and therapeutic implications and provide support for the necessity to use neurocognitive assessments in routine clinical examination in patients with $\mathrm{BD}(2-4,71)$.

Cognitive deficits might be also an important factor for the success or failure of therapeutic interventions, both pharmacological and non-pharmacological. As cognitive deficits are a core feature in $\mathrm{BD}$, recommendation should be given for specific cognitive interventions in subgroups of patients with clinically significant cognitive impairments. The effectiveness of different psychosocial interventions might be influenced by cognitive function: so far this has not been thoroughly studied to our knowledge. In this study bipolar patients were offered a cognitive psychoeducational group therapy program [CPEGT, (51)]. This study reports data from a logistic regression analysis looking at the impact of this training on functional outcome and recurrence rate. The sample in this study was characteristic in that patients showed a long duration of illness and a corresponding cognitive impairment.

Our study shows a significant impact of CPEGT on functional outcome in patients with $\mathrm{BD}$; to a lesser degree also CPT-IP (false hits) predicted occupational impairment. These findings are clearly preliminary due to the small sample size, but CPEGT seems to be a useful additional therapy to medication to treat patients with long duration of illness. All patients completed the 14-week intervention group, which is consistent with a high acceptability of the treatment strategy. Our study on CPEGT 
supports the concept that specific psychosocial interventions targeting specific aspects of BD can be beneficial $(72,73)$.

Very little is known about the longitudinal course of cognitive deficits and the neuropsychological underpinnings of the dynamics of $\mathrm{BD}$ (74). Improving the knowledge on the development in time of cognitive dysfunction in BD [role of depressive episodes, role of manic episodes, role of mixed episodes, role of specific medications for better or for worse, role of cognitive remediation programs, role of inflammatory mediators $(75)$, role of genetic factors $(76,77)]$ would contribute to identify targets for treatment, to determine possible subtypes of the disorder, and to develop better therapeutic strategies (78, 79). The metaanalytic study by Samamé et al. (13) showed that cognitive deficits remain stable after a follow-up period of 4.62 years. In a study of Demant et al. (80) no significant effect of shortterm cognitive remediation on cognitive dysfunction was found. In our study verbal learning memory deficits at baseline showed correlation with severity of symptoms after 12 months; we therefore suggest that specific intensive and individualized cognitive training may be indicated for this chronic subgroup of patients with $\mathrm{BD}$.

\section{LIMITATIONS}

Limitations of the present study clearly result from the small sample size. While the number of affective episodes in the 12 months prior to the start of the study was correlated to disturbances in sustained attention, it was not possible to assess which polarity of episodes was responsible for this effect.

\section{REFERENCES}

1. Tohen M, Zarate CA Jr., Hennen J, Khalsa HM, Strakowski SM, GebreMedhin P, et al. The McLean-Harvard First-Episode Mania Study: prediction of recovery and first recurrence. Am J Psychiatry. (2003) 160:2099107. doi: 10.1176/appi.ajp.160.12.2099

2. Martinez-Aran A, Scott J, Colom F, Torrent C, Tabares-Seisdedos R, Daban $\mathrm{C}$, et al. Treatment nonadherence and neurocognitive impairment in bipolar disorder. J Clin Psychiatry. (2009) 70:1017-23. doi: 10.4088/JCP.08m04408

3. Sachs G, Schaffer M, Winklbaur B. Cognitive deficits in bipolar disorder. Neuropsychiatr. (2007) 21:93-101. doi: 10.5414/NEPBand21093

4. Martino DJ, Strejilevich SA, Marengo E, Ibanez A, Scapola M, Igoa A. Toward the identification of neurocognitive subtypes in euthymic patients with bipolar disorder. J Affect Disord. (2014) 167:118-24. doi: 10.1016/j.jad.2014. 05.059

5. Bourne C, Aydemir Ö, Balanzá-Martínez V, Bora E, Brissos S, Cavanagh JT, et al. Neuropsychological testing of cognitive impairment in euthymic bipolar disorder: an individual patient data meta-analysis. Acta Psychiatr Scand. (2013) 128:149-62. doi: 10.1111/acps.12133

6. Baş TÖ, Poyraz CA, Baş A, Poyraz BÇ, Tosun M. The impact of cognitive impairment, neurological soft signs and subdepressive symptoms on functional outcome in bipolar disorder. J Affect Disord. (2015) 174:33641. doi: 10.1016/j.jad.2014.12.026

7. Aminoff SR, Hellvin T, Lagerberg TV, Berg AO, Andreassen OA, Melle I. Neurocognitive features in subgroups of bipolar disorder. Bipolar Disord. (2013) 15:272283. doi: 10.1111/bdi.12061

8. Torres IJ, Kozicky J, Popuri S, Bond DJ, Honer WG, Lam RW, et al. 12-month longitudinal cognitive functioning in patients recently diagnosed with bipolar disorder. Bipolar Disord. (2014) 16:159-71. doi: 10.1111/bdi.12184

\section{CONCLUSION}

Compared to healthy controls bipolar patients show cognitive impairment.

The extent of cognitive impairment appears to impact occupational disability and clinical outcome.

Occupational impairment was reduced by cognitive psychoeducational group therapy (CPEGT).

\section{DATA AVAILABILITY STATEMENT}

The datasets generated for this study are available on request to the corresponding author.

\section{ETHICS STATEMENT}

The studies involving human participants were reviewed and approved by Medical University of Vienna, Austria. The patients/participants provided their written informed consent to participate in this study.

\section{AUTHOR CONTRIBUTIONS}

GS wrote the manuscript, performed the statistics, coordinated, and performed the clinical study. $\mathrm{AB}$ contributed to the realization of group therapy and cognitive tests. RJ performed the statistics. GL planned, coordinated, and performed the clinical study. AE wrote the manuscript, reviewed the existing literature, and contributed to the recruitment of patients. All authors contributed to the article and approved the submitted version.

9. Brambilla P, Macdonald AW III, Sassi RB, Johnson MK, Mallinger AG, Carter $\mathrm{CS}$, et al. Context processing performance in bipolar disorder patients. Bipolar Disord. (2007) 9:230-7. doi: 10.1111/j.1399-5618.2007.00398.x

10. Brambilla P, Cerruti S, Bellani M, Perlini C, Ferro A, Marinelli V, et al. Shared impairment in associative learning in schizophrenia and bipolar disorder. Prog Neuropsychopharmacol Biol Psychiatry. (2011) 35:10939. doi: 10.1016/j.pnpbp.2011.03.007

11. Palsson E, Figueras C, Johansson GM, Ekman CJ, Hultman B, Östlind J, et al. Neurocognitive function in bipolar disorder: a comparison between bipolar I and II disorder and matched controls. BMC Psychiatry. (2013) 13:1-9. doi: 10.1186/1471-244X-13-165

12. Levy B, Medina AM, Weiss RD. Cognitive and psychosocial functioning in bipolar disorder with and without psychosis during early remission from an acute mood episode: a comparative longitudinal study. Compr Psychiatry. (2013) 54:618-26. doi: 10.1016/j.comppsych.2012.12.018

13. Samamé C, Martino DJ, Strejilevich SA. Longitudinal course of cognitive deficits in bipolar disorder: a meta-analytic study. J Affect Disord. (2014) 164:130-8. doi: 10.1016/j.jad.2014.04.028

14. Santos JL, Aparicio A, Bagney A, Sanchez-Morla EM, Rodriguez-Jimenez R, Mateo J, et al. A five-year follow-up study of neurocognitive functioning in bipolar disorder. Bipolar Disord. (2014) 170:334-41. doi: 10.1111/bdi.12215

15. Chakrabarty T, Kozicky JM, Torres IJ, Lam RW, Yatham LN. Verbal memory impairment in new onset bipolar disorder: relationship with frontal and medial temporal morphology. World J Biol Psychiatry. (2015) 16:24960. doi: 10.3109/15622975.2014.1000373

16. Bauer IE, Ouyang A, Mwangi B, Sanches M, Zunta-Soares GB, Keefe RS, et al. Reduced white matter integrity and verbal fluency impairment in young adults with bipolar disorder: a diffusion tensor imaging study. J Psychiatr Res. (2015) 62:115-22. doi: 10.1016/j.jpsychires.2015.01.008 
17. Rosa AR, González-Ortega I, González-Pinto A, Echeburúa E, Comes M, Martínez-Àran A, et al. One-year psychosocial functioning in patients in the early vs. late stage of bipolar disorder. Acta Psychiatr Scand. (2012) 125:335-41. doi: 10.1111/j.1600-0447.2011.01830.x

18. Wingo AP, Harvey PD, Baldessarini RJ. Neurocognitive impairment in bipolar disorder patients: functional implications. Bipolar Disord. (2009) 11:11325. doi: 10.1111/j.1399-5618.2009.00665.x

19. Sanchez-Moreno J, Martinez-Aran A, Tabarés-Seisdedos R, Torrent C, Vieta E, AyusoMateos JL. Functioning and disability in bipolar disorder: an extensive review. Psychother Psychosom. (2009) 78:285-97. doi: 10.1159/000228249

20. Vlad M, Raucher-Chéné D, Henry A, Kaladjian A. Functional outcome and social cognition in bipolar disorder: is there a connection? Eur Psychiatry. (2018) 52:116-25. doi: 10.1016/j.eurpsy.2018.05.002

21. Van Rheenen TE, Rossell SL. Objective and subjective psychosocial functioning in bipolar disorder: an investigation of the relative importance of neurocognition, social cognition and emotion regulation. J Affect Disord. (2014) 162:134-41. doi: 10.1016/j.jad.2014.03.043

22. Bonnín CM, González-Pinto A, Solé B, Reinares M, González-Ortega I, Alberich S, et al. Verbal memory as a mediator in the relationship between subthreshold depressive symptoms and functional outcome in bipolar disorder. J Affect Disord. (2014) 160:50-4. doi: 10.1016/j.jad.2014.02.034

23. Schoeyen HK, Melle I, Sundet K, Aminoff SR, Hellvin T, Auestad BH, et al. Occupational outcome in bipolar disorder is not predicted by premorbid functioning and intelligence. Bipolar Disord. (2013) 15:294305. doi: 10.1111/bdi.12056

24. Ryan KA, Vederman AC, Kamali M, Marshall D, Weldon AL, McInnis MG, et al. Emotion perception and executive functioning predict work status in euthymic bipolar disorder. Psychiatry Res. (2013) 210:4728. doi: 10.1016/j.psychres.2013.06.031

25. Bonnín CM, Reinares M, Hidalgo-Mazzei D, Undurraga J, Mur M, Sáez C, et al. Predictors of functional outcome after a manic episode. J Affect Disord. (2015) 182:121-5. doi: 10.1016/j.jad.2015.04.043

26. Solé B, Jiménez E, Torrent C, Reinares M, Bonnín CDM, Torres $\mathrm{I}$, et al. Cognitive impairment in bipolar disorder: treatment and prevention strategies. Int J Neuropsychopharmacol. (2017) 20:670-80. doi: 10.1093/ijnp/pyx032

27. Panhorst H, Ramacher P, Wagener R, Erfurth A. Psychoedukation bei bipolaren Störungen. Nervenheilkunde. (2001) 20(Suppl. 2):34-8.

28. Colom F, Vieta E, Martinez-Aran A, Reinares M, Goikolea JM, Benabarre A, et al. A randomized trial on the efficacy of group psychoeducation in the prophylaxis of recurrences in bipolar patients whose disease is in remission. Arch Gen Psychiatry. (2003) 60:402-7. doi: 10.1001/archpsyc.60.4.402

29. Erfurth A, Dobmeier G, Zechendorff M. Kurzpsychoedukation für bipolare Patienten. Stuttgart: Thieme Verlag (2005).

30. Michalak EE, Yatham LN, Wan DD, Lam RW. Perceived quality of life in patients with bipolar disorder. Does group psychoeducation have an impact? Can J Psychiatry. (2005) 50:95-100. doi: 10.1177/070674370505000204

31. Fiorillo A, Del Vecchio V, Luciano M, Sampogna G, De Rosa C, Malangone C, et al. Efficacy of psychoeducational family intervention for bipolar I disorder: a controlled, multicentric, real-world study. J Affect Disord. (2014) 172C:291-9. doi: 10.1016/j.jad.2014.10.021

32. Barnes CW, Hadzi-Pavlovic D, Wilhelm K, Mitchell PB. A web-based preventive intervention program for bipolar disorder: outcome of a 12months randomized controlled trial. J Affect Disord. (2015) 174:48592. doi: 10.1016/j.jad.2014.11.038

33. Bond K, Anderson IM. Psychoeducation for relapse prevention in bipolar disorder: a systematic review of efficacy in randomized controlled trials. Bipolar Disord. (2015) 17:349-62. doi: 10.1111/bdi.12287

34. Depp CA, Ceglowski J, Wang VC, Yaghouti F, Mausbach BT, Thompson WK, et al. Augmenting psychoeducation with a mobile intervention for bipolar disorder: a randomized controlled trial. J Affect Disord. (2015) 174:2330. doi: 10.1016/j.jad.2014.10.053

35. Tsapekos D, Seccomandi B, Mantingh T, Cella M, Wykes T, Young AH. Cognitive enhancement interventions for people with bipolar disorder: a systematic review of methodological quality, treatment approaches, and outcomes. Bipolar Disord. (2019) 22:216-30. doi: 10.1111/bdi.12848
36. Tsapekos D, Strawbridge R, Cella M, Wykes T, Young AH. Do we really need a "new" cognitive therapy for bipolar disorder? Paradigm refinements and treatment mechanisms for cognitive remediation. Bipolar Disord. (2020) 22:213-5. doi: 10.1111/bdi.12890

37. Miklowitz DJ. Adjunctive psychotherapy for bipolar disorder: state of the evidence. Am J Psychiatry. (2008) 165:140819. doi: 10.1176/appi.ajp.2008.08040488

38. Dijk SV, Jeffrey J, Katz MR. A randomized, controlled, pilot study of dialectical behavior therapy skills in a psychoeducational group for individuals with bipolar disorder. J Affect Disord. (2013) 145:38693. doi: 10.1016/j.jad.2012.05.054

39. Lauder S, Chester A, Castle D, Dodd S, Gliddon E, Berk L, et al. A randomized head to head trial of MoodSwings.net.au: an Internet based self-help program for bipolar disorder. I Affect Disord. (2015) 171:13. doi: 10.1016/j.jad.2014.08.008

40. van der Voort TY, van Meijel B, Goossens PJ, Hoogendoorn AW, Draisma S, Beekman A, et al. Collaborative care for patients with bipolar disorder: randomised controlled trial. Br J Psychiatry. (2015) 206:393400. doi: 10.1192/bjp.bp.114.152520

41. Zyto S, Jabben N, Schulte PF, Regeer BJ, Kupka RW. A pilot study of a combined group and individual functional remediation program for patients with bipolar I disorder. J Affect Disord. (2016) 194:915. doi: 10.1016/j.jad.2016.01.029

42. Haffner P, Quinlivan E, Fiebig J, Sondergeld LM, Strasser ES, Adli $\mathrm{M}$, et al. Improving functional outcome in bipolar disorder: a pilot study on metacognitive training. Clin Psychol Psychother. (2018) 25:508. doi: $10.1002 /$ cpp. 2124

43. Zhang Y, Ma X, Liang S, Yu W, He Q, Zhang J, et al. Social cognition and interaction training (SCIT) for partially remitted patients with bipolar disorder in China. Psychiatry Res. (2019) 274:377-82. doi: 10.1016/j.psychres.2019.03.002

44. Weintraub MJ, Axelson DA, Kowatch RA, Schneck CD, Miklowitz DJ. Comorbid disorders as moderators of response to family interventions among adolescents with bipolar disorder. J Affect Disord. (2019) 246:75462. doi: 10.1016/j.jad.2018.12.125

45. Perugi G, Hantouche E, Vannucchi G, Pinto O. Cyclothymia reloaded: a reappraisal of the most misconceived affective disorder. J Affect Disord. (2015) 183:119-33. doi: 10.1016/j.jad.2015.05.004

46. Cakir S, Bensusan R, Akca ZK, Yazici O. Does a psychoeducational approach reach targeted patients with bipolar disorder? J Affect Disord. (2009) 119:1903. doi: 10.1016/j.jad.2009.08.016

47. de Barros Pellegrinelli K, de O Costa LF, Silval KI, Dias VV, Roso MC, Bandeira M, et al. Efficacy of psychoeducation on symptomatic and functional recovery in bipolar disorder. Acta Psychiatr Scand. (2013) 127:1538. doi: 10.1111/acps.12007

48. Torrent C, Bonnín CM, Martínez-Arán A, Valle J, Amann BL, GonzálezPinto A, et al. Efficacy of functional remediation in bipolar disorder: a multicenter randomized controlled study. Am J Psychiatry. (2013) 170:8529. doi: 10.1176/appi.ajp.2012.12070971

49. Solé B, Bonnín CM, Mayoral M, Amann BL, Torres I, González-Pinto A, et al. Functional remediation for patients with bipolar II disorder: improvement of functioning and subsyndromal symptoms. Eur Neuropsychopharmacol. (2015) 25:257-64. doi: 10.1016/j.euroneuro.2014.05.010

50. Bonnín CM, Torrent C, Arango C, Amann BL, Solé B, González-Pinto A, et al. Functional remediation in bipolar disorder: 1-year follow-up of neurocognitive and functional outcome. Br J Psychiatry. (2016) 208:8793. doi: 10.1192/bjp.bp.114.162123

51. Schaub A, Bernhard B, Gauck L. Kognitiv-psychoedukative Therapie bei bipolaren Erkrankungen. Ein Therapiemanual. Göttingen: Hogrefe Verlag (2004).

52. First MG, Spitzer RL, Gibbon M, Williams JB. Structured Clinical Interview for DSM-IV Patient Edition (SCID-P). New York, NY: Biometrics Research Department, State Psychiatric Institute (1995). doi: 10.1037/t07827-000

53. Sheehan DV, Lecrubier Y, Harnett-Sheehan K, Amorim P, Janavs J, Weiller E, et al. The M.I.N.I. International Neuropsychiatric Interview (M.I.N.I.): the development and validation of a structured diagnostic psychiatric interview. $J$ Clin Psychiatry. (1998) 59(Suppl. 20):22-33. doi: 10.1037/t18597-000 
54. Beck AT, Ward CH, Mendelson M, Mock J, Erbaugh J. An inventory for measuring depression. Arch Gen Psychiatry. (1961) 4:561-71. doi: 10.1001/archpsyc.1961.01710120031004

55. Krüger S, Bräunig P, Shugar G. Manie-Selbstbeurteilungsskala (MSS). Göttingen: Beltz (1997).

56. Bech P, Rafaelsen OJ, Kramp P, Bolwig TG. The mania rating scale: scale construct and inter-observer agreement. Neuropharmacology. (1978) 17:4301. doi: 10.1016/0028-3908(78)90022-9

57. Licht RW, Qvitzau S, Allerup P, Bech P. Validation of the Bech-Rafaelsen Melancholia Scale and the Hamilton Depression Scale in patients with major depression: is the total score a valid measure of illness severity? Acta Psychiatr Scand. (2005) 111:144-9. doi: 10.1111/j.1600-0447.2004.00440.x

58. Guy W. ECDEU Assessment Manual for Psychopharmacology-Revised (DHEW Publ No ADM 76-338). Rockville, MD: Department of Health, Education, and Welfare, Public Health Service, Alcohol, Drug Abuse, and Mental Health Administration, NIMH Psychopharmacology Research Branch, Division of Extramural Research Programs (1976). p. 218-22.

59. Sheehan DV, Harnett-Sheehan K, Raj BA. The measurement of disability. Int Clin Psychopharmacol. (1996) 11(Suppl. 3):8995. doi: 10.1097/00004850-199606003-00015

60. Lehrl S. Manual MWT-B. Erlangen: Straube (1977).

61. Cornblatt BA, Risch NJ, Faris G, Friedman D, Erlenmeyer-Kimling L. The continuous performance test, identical pairs version (CPT-IP): I. New findings about sustained attention in normal families. Psychiatry Res. (1988) 26:22338. doi: 10.1016/0165-1781(88)90076-5

62. Heaton RK. Wisconsin Card Sorting Test Manual. Odessa, FL: Psychological Assessment Resources (1981).

63. Helmstaedter C, Lendt M, Lux S. Verbaler Lern- und Merkfähigkeitstest (VLMT). Göttingen: Beltz (2001).

64. Aschenbrenner S, Rucha O, Lange KW. Regensburger Wortflüssigkeitstest (RWT). Göttingen: Hogrefe Testzentrale (2001).

65. Lam DH, Bright J, Jones S, Hayward P, Schuck N, Chisholm D, et al. Cognitive therapy for bipolar illness - A pilot study of relapse prevention. Cognit Ther Res. (2000) 24:503-20. doi: 10.1023/A:1005557911051

66. Schaub A, Neubauer N, Bernhard B, Born C, Möller HJ, Grunze H. Cognitive psychoeducational group programme for bipolar disorder: pilot study with two-year follow up. Fortschr Neurol Psychiatr. (2013) 81(Suppl. 1):30-4. doi: 10.1055/s-0033-1335242

67. Vasak G, Katschnig H. Sturzfliegen: Leben in Depressionen und Manien. Zürich: Rüffer \& Rub (2001).

68. Breit-Gabauer B, Berg A, Demelbauer S, Schrott A, Stampfer I, Lenz G. Prodromes and coping strategies in patients with bipolar disorder. Verhaltenstherapie. (2010) 20:183191. doi: 10.1159/000319447

69. Lenz, G. Cognitive-psychoeducative group-therapy vs. TAU with additional information group: a randomized controlled study. Eur Psychiatry. (2010) 25(Suppl. 1):19. doi: 10.1016/S0924-9338(10)7 0019-5

70. Erfurth A, Perugi G. Rapid cycling. In: Kasper S, Hirschfeld RMA, editors. Handbook of Bipolar Disorder. New York, London: Taylor \& Francis (2005). p. 201-12.
71. Bauer IE, Keefe RS, Sanches M, Suchting R, Green CE, Soares JC. Evaluation of cognitive function in bipolar disorder using the Brief Assessment of Cognition in Affective Disorders (BAC-A). J Psychiatr Res. (2015) 60:816. doi: 10.1016/j.jpsychires.2014.10.002

72. Miziou S, Tsitsipa E, Moysidou S, Karavelas V, Dimelis D, Polyzoidou V, et al. Psychosocial treatment and interventions for bipolar disorder: a systematic review. Ann Gen Psychiatry. (2015) 14:19. doi: 10.1186/s12991-015-0057-Z

73. Kim Y, Kwon A, Min D, Kim S, Jin MJ, Lee SH. Neurophysiological and psychological predictors of social functioning in patients with schizophrenia and bipolar disorder. Psychiatry Investig. (2019) 16:71827. doi: $10.30773 /$ pi.2019.07.28

74. Wessa M, Perlini C, Brambilla P. Neuropsychological underpinnings of the dynamics of bipolar disorder. Epidemiol Psychiatr Sci. (2015) 9:15. doi: 10.1017/S2045796015000098

75. Bauer IE, Pascoe MC, Wollenhaupt-Aguiar B, Kapczinski F, Soares JC. Inflammatory mediators of cognitive impairment in bipolar disorder. $J$ Psychiatr Res. (2014) 56:18-27. doi: 10.1016/j.jpsychires.2014.04.017

76. Frazier TW, Youngstrom EA, Frankel BA, Zunta-Soares GB, Sanches M, Escamilla $\mathrm{M}$, et al. Candidate gene associations with mood disorder, cognitive vulnerability, and fronto-limbic volumes. Brain Behav. (2014) 4:418-30. doi: 10.1002/brb3.226

77. Budde M, Friedrichs S, Alliey-Rodriguez N, Ament S, Badner JA, Berrettini WH, et al. Efficient region-based test strategy uncovers genetic risk factors for functional outcome in bipolar disorder. Eur Neuropsychopharmacol. (2019) 29:156-70. doi: 10.1016/j.euroneuro.2018.10.005

78. Breitborde NJ, Dawson SC, Woolverton C, Dawley D, Bell EK, Norman $\mathrm{K}$, et al. A randomized controlled trial of cognitive remediation and dcycloserine for individuals with bipolar disorder. BMC Psychol. (2014) 2:41. doi: 10.1186/s40359-014-0041-4

79. Lahera G, Bayón C, Fe Bravo-Ortiz M, Rodríguez-Vega B, Barbeito S, Sáenz $M$, et al. Mindfulness-based cognitive therapy versus psychoeducational intervention in bipolar outpatients with sub-threshold depressive symptoms: a randomized controlled trial. BMC Psychiatry. (2014) 14:215. doi: 10.1186/s12888-014-0215-X

80. Demant KM, Vinberg M, Kessing LV, Miskowiak KW. Effects of short-term cognitive remediation on cognitive dysfunction in partially or fully remitted individuals with bipolar disorder: results of a randomised controlled trial. PLoS ONE. (2015) 10:e0127955. doi: 10.1371/journal.pone.0127955

Conflict of Interest: The authors declare that the research was conducted in the absence of any commercial or financial relationships that could be construed as a potential conflict of interest.

Copyright (c) 2020 Sachs, Berg, Jagsch, Lenz and Erfurth. This is an open-access article distributed under the terms of the Creative Commons Attribution License (CC $B Y)$. The use, distribution or reproduction in other forums is permitted, provided the original author(s) and the copyright owner(s) are credited and that the original publication in this journal is cited, in accordance with accepted academic practice. No use, distribution or reproduction is permitted which does not comply with these terms. 